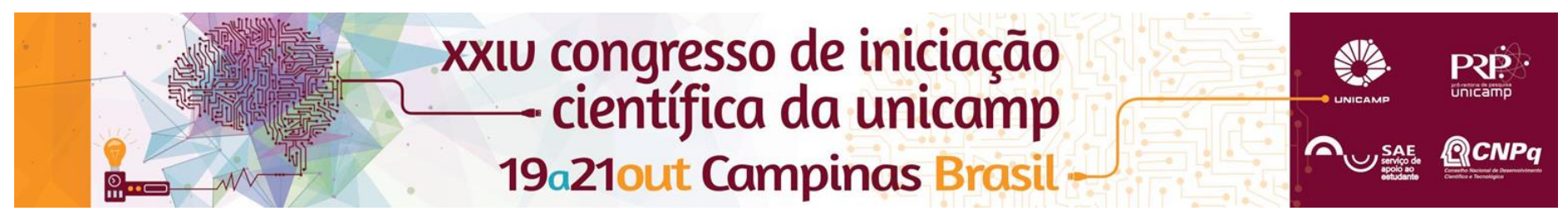

\title{
Efeito dos polimentos químico e mecânico sobre a dureza e rugosidade de resinas acrílicas ativadas por diferentes ciclos de polimerização
}

\author{
Bianca L. Folli*, Moises C. F. Nogueira, Rafael L. X. Consani
}

\section{Resumo}

O objetivo foi avaliar o efeito dos polimentos mecânico e químico sobre a dureza e rugosidade de resinas acrílicas. Foram utilizadas resinas Clássico e Onda Cryl, e Vipi e Vipi Wave. As amostras foram submetidas ao acabamento convencional e polimento: A-mecânico e B-químico. A dureza dos grupos A e B foram de 23,9 e 24,4 respectivamente, diferindo estatisticamente apenas para a VipiWave. A rugosidade entre A e B $(0,5849$ e 2,3704) foram com diferença estatística entre todas as marcas.

\section{Palavras-chave:}

Resina acrílica, propriedades físicas, polimerização.

\section{Introdução}

O objetivo foi avaliar o efeito dos polimentos mecânico e químico sobre a dureza e rugosidade de resinas acrílicas ativadas por diferentes ciclos de polimerização. Foram utilizadas resinas acrílicas Clássico (convencional) e Onda Cryl (micro-ondas), e Vipi (convencional) e Vipi Wave (micro-ondas). Amostras das resinas foram confeccionadas em matrizes retangulares (Figura 1) de alumínio $(65 \times 10 \times 3 \mathrm{~mm})$, incluídas em muflas metálicas para convencionais e plásticas para micro-ondas com gesso pedra. A proporção pó/líquido e mistura das resinas acrílicas foi efetuada de acordo com as recomendações dos fabricantes e a prensagem das muflas pelo método convencional. Após polimerização nos ciclos A- água aquecida a $74^{\circ} \mathrm{C}$ por 9 horas e Bmicro-ondas com $1400 \mathrm{~W}$ de potência $(30 \%$ da potência por 3 minutos, $0 \%$ da potência por 4 minutos e $60 \%$ da potência por 3 minutos - Onda Cryl) e micro-ondas com $1400 \mathrm{~W}$ de potência (10\% da potência por 20 minutos e $30-40 \%$ da potência por 5 minutos - Vipi Wave), as amostras foram demufladas após esfriamento em temperatura ambiente e submetidas ao processo de acabamento convencional e polimento: a) mecânico com pastas abrasivas utilizando disco de feltro acoplado à politriz, e b) químico no dispositivo PQ 9000 (Termotron, Piracicaba, SP) com polidor químico aquecido (PoliQuim; Clássico) atuando por 10 segundos, secagem por 20 segundos e lavagem por 20 segundos em água corrente. A dureza e a rugosidade foram mensuradas após armazenagem em água a $37^{\circ} \mathrm{C}$ por 24 horas. A dureza Knoop foi verificada em microdurômetro Shimadzu HMV - 2000, calibrado com carga de 50 g por 10 segundos, realizadas em três penetrações por cada corpo-de-prova (centro e extremidades). A rugosidade de superfície foi avaliada por meio de rugosímetro Surfcorder SE 1700 (Kosaka).

\section{Resultados e Discussão}

A média de dureza dos grupos polimento mecânico (a) e polimento químico (b) foram de 23,9 e 24,4 respectivamente. $\mathrm{Na}$ rugosidade as médias entre polimentos (a) e (b), foram de 0,5849 e 2,3704 respectivamente.

Figura 1 - Esquema da matriz para confecção das amostras.

\section{Conclusão}

A média de dureza dos grupos polimento mecânico (a) e polimento químico (b) foram de 23,9 e 24,4 respectivamente, diferindo estatisticamente apenas para a marca comercial VipiWave. Quanto a rugosidade, as médias entre polimentos (a) e (b), foram de 0,5849 e 2,3704 respectivamente, com diferença estatística entre todas as marcas comerciais.

\section{Agradecimentos}

Os autores agradecem o apoio do CNPq/SAE/UNICAMP para o desenvolvimento da pesquisa na Faculdade de Odontologia de Piracicaba da Universidade Estadual de Campinas, SP, Brasil.

Anusavice KJ. Phillips Materiais Dentários. 12. ed., Rio de Janeiro; Elsevier: 2013.

Blagojevic V, Murphy VM. Microwave polymerization of denture base materials. A comparative study. J Oral Rehabil. 1999;26(10):804-808.

Braun KO, Mello JAN, Rached RN, Del Bel Cury AA. Surface texture and some properties of acrylic resins submitted to chemical polishing. J Oral Rehabil. 2003; 30 (1): $91-98$

Consani RLX, Vieira EB, Mesquita MF, Mendes WB, Arioli-Filho JN. Effect of microwave disinfection on physical and mechanical properties of acrylic resins. Braz Dent J. 2008; 19(4): 348-353.

Consani RLX, Vieira ML, Mesquita MF, Sinhoreti MAC, Guiraldo RD, Nóbilo MAA. Effect of polymerization cycles on the linear dimensional change hardness and impact strength of denture base acrylic resins. Minerva Stomatol. 2012; 61(6):273-282.

Consani RLX, Chorwat V, Mesquita MF, Consani S, Santos MBF, Henriques GEP. Effect of simulated microwave disinfection on the linear dimensional change, hardness and impact strength of acrylic resins cured using different curing cycles. Minerva Stomatol. 2014; 63(5):145-154.

Gay WD, King GE. An evaluation of the cure of acrylic resin by three methods. J Prosthet Dent. 1979; 42 (4): 437-440.

Goiato MC, Vedovatto E, Amantéia DCZ, Gennari Filho H, Marinho MLVD. Análise da movimentação dos dentes artificiais em próteses totais superiores. Influência do tipo de polimento. Cienc Odontol Bras. 2006; 9 (1):6-16. 